\title{
Note on some Formosan Fermentation Organisms.
}

By

K. Saito.

In various parts of the Formosan Island, one can purchase many kinds of alcoholic beverages, which are prepared by distilling certain fermentation products or by admixing some essence to those spirituous liquids obtained. In practice, common rice or its variety, glutinous rice (sometimes also sweet potato) is used as the raw material and the alcoholic fermentation follows on the saccharification of the starch contained in the material used.

The process of obtaining the spirituous liquid may be divided into three stages, viz. Koji-making, mashing, and distilling. It is said that primitive but very ingenious methods are used. The Koji seems to contain the germs of fungi useful for the saccharification of starch and for the subsequent alcoholic fermentation. This remarkable agent also brings about the fermentation of steamed starch meals or saccharine solutions, to which it has been added, and transforms them into a liquid emitting the spirituous odour. Hence, as is already known of many beverages in Eastern Asia, the fermentation may be regarded as metabiotic.

Whatever be the kind of the beverage produced, the Koji used in Formosa is only of two kinds, one called "Beni-koji" and other "Shiro-koji." Uyeda investigated on the one hand, the flora of the "Beni-koji" and found Monascus purpureus WENT and a yeast to be the essential forms constantly met

1) This Magazine, 1902, Vol. 15, No. 178, p. 160. 
with; but his researches threw no light on the nature of that species which produces alcohol during the mashing and is contained in the Koji itself. On the other hand, he notes about the "Shiro-koji" merely that it is mainly composed of a species of Mucor. Usamr, in his investigation of the "Awamori," mentions the presence of two kinds of yeast in the "Shiro-koji," but he gives no evidence of having examined the matter in detail.

By the kindness of Messrs. Kawakami and Nakahara I have been able to get both kinds of the Koji, mash, and some of the beverages on the market. Of these, the biological analysis was undertaken and it will be obvious that the problems which present themselves are two, namely to find out the fungus which acts on starch to convert it into a fermentable form and to identify the yeast which has to do with the decomposition of sugar into alcohol and carbonic anhydride.

The examination has revealed the existence of various organisms, of which some are essential and others mere intruders or foreign organisms having nothing to do with the changes in question. I venture to hope the following notes will be found of some interest.

\section{Beni-koji.}

The "Beni-koji" presents in shape and size the appearance of a rice grain and is of a dark purple red colour. When in a dried state, the Koji-grain is brittle and very apt to break, easily changing to powder of the same colour. By the usual method I have isolated Monascus purpureus and a yeast, as the constant and essential components of the Koji, which I. have examined.

(1) Monascus purpureus Went.

This species was at first found in "Ang-khak" of Java by

1) Report of the College of Teclnology, Imperial University, Tokyo, 1901, No. 3, p. 15. (In Japanese). 
WENT, ${ }^{1)}$ whose investigations have so far been directed almost entirely to elucidating the morphology and physiology of that fungus. The physical and chemical properties of the pigment, which this species produces, are considered in the papers of Vordermann, ${ }^{2)}$ Prinsen Geerligs ${ }^{3)}$ and Boorsma. ${ }^{4)}$ Passing over the conflicting views as to the development and systematic position of this species, in the following I will present some remarks on the enzymic action of this fungus.

A sterilized mass of steamed rice-bran was sown with the spores of purely cultured $M$. purpureus and kept in an incubator at the temperature of $35^{\circ} \mathrm{c}$. When the fungus had fully grown over the rice-bran and it presented a purple red mass bound together by a white mycelium, to the whole mass an equal amount of water was added and well mixed; then with stirring occasionally at the ordinary temperature, the mixture was left about 24 hours. The mixture was then filtered, and to the filtrate was added two or three times the volume of $90-95 \%$ alcohol, and the precipitates collected and dried by means of vacuum evaporation. The aqueous solution of the dried mass after filtering was used for the test of the enzymic actions.

(a) Amylase. 10 c.c. of gelatinised starch allowed to cool to $50^{\circ} \mathrm{c}$, and mixed with $1 \mathrm{c} \mathrm{c}$. of the enzyme solution above mentioned. The mixture was kept at this temperature. The opalescense of the starch paste disappeared in about 30 minutes, and after $1 \frac{112}{2}$ hour it gave a purple red colour with iodine solution. At the same time the solution began to reduce the Ferling's solution. Unfortunately the amylolytic power of this fungus was not determined quantitatively, so that it is hard to say whether or not it is as strong as those of other kinds of diastase. But I am continuing the comparative study of the amylases to be obtained from the useful fungi found in the Eastern Asia, and hope to determine the nature of sugars produced from starch by their action.

\footnotetext{
1) Ann. des sciences nat., B tan., 1895, 8 sér., Vol 1, p. 1.

2) Geneeskundig Tijdschrift voor Nederl. Indie, 1894, Vol. 34, No. 5.

3) Chem.-Ztg, 1895, , Vol. 19, p. 1311.

4) Chem. Centr., 1896, Bd I, p. 1130 .
} 
(b) Invertase. 50 c.c. of $5 \%$ cane sugar solution was mixed with 5 c.c. of the enzyme solution and allowed to stand for 24 hours in the laboratory, of course care being taken as regards the aseptic state of the mixture. No inversion of cane sugar took place, and it had no greater reducing action on F EHLING's solution, than had the control solution.

The absence of invertase in this fungus was verified moreover by LINDNER's fermentation test. ${ }^{1)}$ It was proceeded with in the following way :-

As in the sugar solution cultivated with this fungus a weak alcoholic fermentation occurs, I have examined whether carbonic anhydride is produced or not in the closed cavity of hollow slide containing an aqueous solution of carbohydrate and a small piece of dissected fresh mycelium. The result is here tabulated as follows: ( + denotes the occurrence of gas production, and - the absence of it).

$\begin{array}{ll}\text { dextrose } & + \\ \text { levulose } & + \\ \text { galactose } & - \\ \text { arabinose } & - \\ \text { maltose } & + \\ \text { saccharose } & - \\ \text { lactose } & - \\ \text { melibiose } & - \\ \text { raffinose } & - \\ \text { inulin } & - \\ \text { dextrin } & + \\ \text { u-methylglucoside } & -\end{array}$

From the preceding table we see that the fungus can ferment dextrose, levulose, maltose and dextrin, whereas it does not act on the other carbohydrates examined. While this experiment assures us that the species does not secrete invertase, it leads us at the same time to infer the presence of maltase.

1) Mikroskopische Betriebskontrolle in den Gährungsgewerben, vierte Auflage, 1906, p. 230 . 
(c) Proteolytic enzyme. To a test tube containing sterilised and coagulated gelatine was added a small quantity of the enzyme solution above mentioned, and the tube was left at the ordinary temperature, keeping the solution in an aseptic condition. The gelatine dissolved very slowly from its upper surface. The result distirctly proves that the fungus can secrete a weak proteolytic enzyme, and also coincides with the fact, that the streak culture of this species on gelatine slowly dissolves the medium.

(d) Rennet. This species grows in common milk very slowly, and the milk becomes gradually clear and somewhat reddish in colour, while during the culture there is to be observed no sign of coagulation of milk-casein. The enzyme solution above mentioned has also never created any coagulum by mixing with fresh milk. The fungus may be regarded as one that does not secrete rennet.

(e) Oxidising enzyme and katalase. By mixing the above mentioned enzyme solution with a small quantity of hydrogenperoxide, an enormous production of oxygen took place. The mixture turned bluish in colour when tincture of guajak-resin was added again to it. These reactions did not happen when the solution used was at first boiled. The results arrived at prove distinctly the existence of katalase and peroxydase in the solution used. Nevertheless, the solution produced no blackning of tyrosin, which shows the absence of the tyrosinase in that solution.

$$
\text { (2) "Beni-koji"-Yeast. }
$$

The germs of this yeast occur abundantly in the "Benikoji" and also in the mash which is made by using that agent.

Grown in hopped wort or Koji-decoction, the young cells of the yeast are commonly globoid or ovoid in shape, colourless and translucent, and range from 4 to $7 \mu$ in diameter. They are mostly separated from one another and each isolated cell contains one or more vacuoles, variable in size and enclosed in finely granular protoplasm. In older cultures long sausageshaped cells will be found. 
There is no limit to the size of the colonies. They appear on the gelatine plates at first as round points, gradually growing to white, opaque, dome-shaped clumps and when sufficiently grown, showing numerous notches at the margin and reticulated wrinklings on the surface.

On the surface of fermented wort gradually appear many patches of a small film. The shape of these aerobian cells is more or less ellipsoidal.

I have in vain attempted to obtain the endogenous spores by the usual methods, and cannot decide whether this yeast belongs to genuine saccharomycetes or not.

Dextrose, levulose, galactose, saccharose, maltose, melibiose, raffinose, $\alpha-$ methylglucoside, but not inulin and lactose, are fermentable by this species.

In hopped wort this ycast produced in 20 days 5.89 per cent. (volume) of alcohol, and it shows that, compared with some yeasts, the fermentation-activity is relatively great.

If we compare the facts I have observed about this yeast with what is known of other species, it seems very probable that my species is closely allied with Saccharomyces Awamori InUi. ${ }^{1)}$

\section{Shiro-koji.}

This kind of Koji is one of the so-called "Chinese Yeast." It is round in shape, about $2.5 \mathrm{~cm}$. in diameter and consists of pulverised rice grains. When magnified, it is seen that many large chlamydospores, ycast cells, bacteria etc. are intermingled with the starch grains.

From the Koji I have been able to recognise a large number of fungus germs; among them, as the essential constituents of that Koji, a kind of Rhizopus and a yeast may be mentioned here. The former has a strong power of dissolving starch, sufficient to convert the raw material into fermentable sugars, which by the latter are decomposed to alcohol and carbonic anhydride.

1) Jour. Coll. Sci., Tokyo, Vol. 15, 1901, p. 371. 
While these two specific organisms constitute the "Shirokoji" proper, and are necessary for its action, it contains also some germs of such cosmopolitan species as Penicillium glaucum, Oidium lactis, Aspergillus nidulans etc., which are merely accessory or foreign organisms, doubtless due to the admixture of spores from outside.

(1) Rhizopus of the "Shiro-koji."

This mould grows very luxuriantly upon such nutritive culture-media as steamed rice, bread, gelatine, Agar-agar etc. The culture produces a snowy, aerial mycelium and only a few sporangia are visible here and there as black spots, scattered over the whole mycelial mass. The walls of the sporangia are coarsely granulated and their stalks are brownish yellow in colour.

The chlamydospores, however, are very abundantly produc$\mathrm{cd}$, and are round or elliptic in shape, of refractile appearance, filled up with finely granulated protoplasm, and tolerably thick-walled. Zygospores have not yet been found.

The vegetative hyphae are colourless (sometimes they contain oil drops, yellowish in colour), variable in thickness, and in contact with the substratum many conspicuous rhizoids are formed.

The optimum temperature for the growth is about $37^{\circ} \mathrm{c}$. The power of dissolving starch is very strong, but the liquifaction of gelatine comes out very slowly. Cultivated in beer wort or koji-decoction, there is produced a small amount of alcohol. ${ }^{1)}$ Dextrose, maltose, soluble starch and mannite, on the one hand, were found to be good carbon-sources, but lactose, saccharose and glycerine less satisfactory. On the other hand, pepton (witte), asparagin, ammonium nitrate and ammonium tartarate may be used, and form good sources of nitrogen.

In form, size and general behaviour, this fungus agrees so

1) The culture produced soma gis-bubbles within the interstices of the grown mycelia. The presence of alcohol was recognised by the odour of distillate and again by the iodoform test. 
well with all the properties of Rhizopus oligosporus, ${ }^{1)}$ that it appears, that the two forms may belong to one species.

As for the behaviour of this fungus towards carbohydrates, I have adopted the Lindner's fermentation test, and at the same time compared it with Rhizopus oligosporus and Chlamydomucor Oryzae. I have here to express my thanks to Prof. Went, of Utrecht, who kindly provided me with the living specimen of the latter species. The results observed were as follows :-

\begin{tabular}{|l|c|c|c|}
\hline \multicolumn{1}{|c|}{ species } & $\begin{array}{c}\text { Rhizopus } \\
\text { oligosporus }\end{array}$ & $\begin{array}{c}\text { Ihlizopus } \\
\text { of the } \\
\text { "Shiro-koji " }\end{array}$ & $\begin{array}{c}\text { Chlamydomucor } \\
\text { Oryzae }\end{array}$ \\
\hline dextrose & ++ & ++ & ++ \\
levulose & ++ & ++ & ++ \\
galactose & + & + & + \\
arabinose & - & - & - \\
maltose & ++ & ++ & ++ \\
saccharose & - & - & ++ \\
lactose & - & - & - \\
melibiose & + & + & + \\
raffinose & + & + & ++ \\
inulin & - & - & ++ \\
o-methylglucoside & - & - & - \\
dextrin & ++ & ++ & ++ \\
\hline
\end{tabular}

$(++$ and + denote strong and weak gas production respectively, and entire absence of it.)

The coincidence of gas production between the "Shiro-koji" fungus and Rhizopus oligosporus in the above table indeed renders it very likely that the two forms may be referred to one species. It is peculiar that they cannot ferment saccharose and also that, as indicated by the usual method of enzyme-proof, the invertase is not secreted by them. Chlamydomucor Oryzae, however, can easily ferment as well as invert saccharose. Although I have hitherto considered Rhizopus oligosporus as a

1) Centralbl. f. Bakt., Abt. II, Bd. XIV, 1905, No. 18/20. p. 623. 
species closely allied to Chlamydomucor Oryzae on account of the scantiness of the sporangium formation, ${ }^{1)}$ they must be regarded hereafter as entirely different species.

Moreover, we have to mention here as the distinctive characters of Rhizopus oligosportus and Ch. Oryzae that the cultures of the former on steamed rice become brownish yellow in colour, while those of the latter take yellowish coloration.

(2) "Shiro-koji" -Yeast.

When a small piece of the "Shiro-koji" is added to saccharine solutions, it induces very active fermentation, and from the white pasty deposit formed at the bottom of the flask, the species is easily separated. The mash made by using the "Shiro-koji" contains also a large number of cells belonging to this yeast.

Young cells are usually globoid in shape, mostly separated from one another. The average size of the cells is 5 to $8 \mu$ in diameter, and they contain one or more vacuoles, unequal in their size and enclosed in hyaline protoplasm. In older cultures we often find long sausage-shaped cells.

The colonies are at first visible as small points, which gradually grow to round, conspicuously dome-shaped, yellowish white clumps. There is no limit to the size of the colonies, but at their surface no wrinkling is to be found.

It is very characteristic of this yeast, that the streak culture on the gelatine shows the liquifaction of the medium within a few days.

Whenever the fermentations were carried on, and even till they were quite finished, no film formed at the surface, except a ring formation along the niveau of the solution used.

The ascospores are almost invariably in pairs. Each spore is round in shape, and ranges from 3 to $5 \mu$ in size.

Dextrose, levulose, galactose, saccharose, maltose, raffinose, but not melibiose, inulin, lactose and $\alpha$-methylglucoside are fermentable by this yeast.

1) In spite of repeated cultivation of Rhizopus oligosporus on several kinds of media, the scantiness of the sporangium formation remains yet constant. 
When this yeast was cultured in hopped wort, it produced in 20 days 5.24 per cent. (volume) of alcohol.

It is not yet certain whether the form noted here is identical with any previously described or new to science, because the most important physiological point of ascospore formation I have been unable to observe fully.

(3) A Mycoderma Yeast.

In some of the separation cultures from the mash made by using the "Shiro-koji" I frequently met with a Mycoderma yeast. A dense white wrinkled dry skin formed at the top of the culture solution. The young cells were oval and averaged about 4 to $6 \mu$ in diameter, rich in protoplasm and containing one or more vacuoles. In the cells from old cultures 1 to 3 small oil drops are visible. The yeast forms no ascospore and it develops no fermentation in saccharine solutions, whatever kind of sugar may be used; and the power of producing acid is also very weak.

I have been unable to identify this form with certainty. However, since this is obviously not concerned with alcoholic fermentation, I did not follow out the details of its properties. November, 1907.

Botanical Institute, College of Science, Imperial University, Tokyo. 